\title{
The Efficacy of Combined Liposuction and Surgical Resection of Deep Fat of the Anterior Abdominal Wall in Abdominoplasty
}

\author{
EHAB Z. AZZAM, M.D.; IMAN L. SALEM, M.D. and HELMY S. EL-WAKEEL, M.D. \\ The Department of Plastic Surgery, Faculty of Medicine, Alexandria University, Egypt
}

\begin{abstract}
Background: Correction of abdominal wall deformities is one of the most frequent procedures in plastic surgery, and the aesthetic, reconstructive, and functional aspects should always be considered. Patients seeking abdominoplasty desire correction of an existing abdominal wall contour deformity resulting from excess skin and fat as well as musculofascial laxity. The objective of this study is to evaluate the safety and outcome of thinning of anterior abdominal wall flap during abdominoplasty from the aesthetic and the functional point of view.
\end{abstract}

Patients and Methods: 20 females complaining of abdominal lipodystrophy, skin laxity and musculoaponeurotic flaccidity were subjected to lipoabdominoplasty with direct surgical resection of the deep fat. Then the results were evaluated from the aesthetic and functional points of view.

Results: The mean hospital stay was $3.75 \pm 0.91$ days (range 3-6 days), two cases were reported with flap dehesince. $(10 \%)$ and only one case of seroma was reported (5\%). $90 \%$ of cases were satisfied and esthetic results as evaluated by a senior plastic surgeon not involved in the study were accepted in 18 cases $(90 \%)$ of cases.

Conclusion: Lipoabdominoplasty with limited supraumblical paramedian undermining with thining of the anterior abdominal wall flap through resection of the deep subscarpal fat, is a powerful and safe body sculpturing tool that can lead to better aesthetic and functional results.

Key Words: Combined - Liposuction - Resection - FatAbdominoplasty.

\section{INTRODUCTION}

The abdomen plays a leading role in the aesthetic image of the human body, and is of prime importance in defining the overall contour of the individual. Functional abdominoplasty was first described by Kelly [1] in 1899 and popularized for cosmetic purposes in 1967 by Pitanguy [2], who introduced the low transverse (i.e., bikini line) incision that could remove lower abdominal scars. Neither Pitanguy nor his predecessors described removal of any adipose tissue beyond the confines of the resected segment.
The subcutaneous tissue of the anterior abdomen is divided into two layers: The superficial (areolar) and the deep (lamellar) layer or the sub-scarpal fat. The Scarpa's fascia or the superficial fascial system of the abdomen (SFS) separates these two planes. Adipose tissue is thick and dense in the superficial layer, which is evenly distributed over the whole abdomen [3].

Many researchers have studied the blood supply of the anterior abdominal wall. In 1975, Taylor and Daniel [4] reported that the superficial inferior epigastric artery traveled superficial to Scarpa's fascia, which Hester et al., [5] and Worseg et al., [6] independently confirmed in 1984. Some authors have verified that all major vasculature of the abdominoplasty flap courses in the layer of adipose tissue superficial to Scarpa's fascia Fig. (1) and have recognized that removal of fat deep to Scarpa's fascia is not accompanied by bleeding or subsequent compromise of the abdominal flap, and so, this fat can be directly excised safely during abdominoplasty [7].

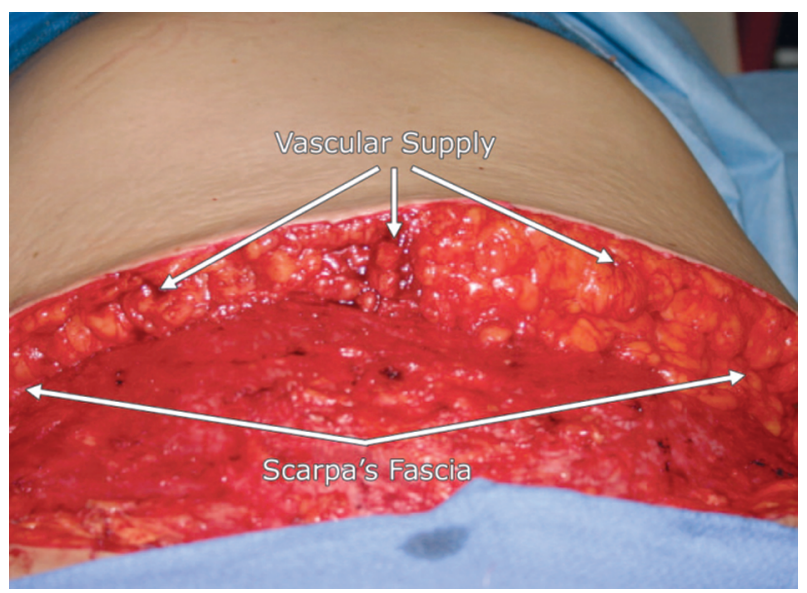

Fig. (1): The two sets of arrows show Scarpa's fascia and the large blood vessels running in the superficial fatty layer. There is no significant blood supply deep to Scarpa's fascia. 
The aim of this study was to evaluate the safety and outcome of thining of anterior abdominal wall flap during abdominoplasty via combined liposuction and sub scarpal fat resection from the aesthetic and the functional point of view.

\section{PATIENTS AND METHODS}

The present study was carried out in the Department of Plastic and Reconstructive Surgery, Alexandria University Hospital on 20 female patients complaining of abdominal lipodystrophy, skin laxity and musculoaponeurotic flaccidity between May of 2015 and May of 2017.

\section{Exclusion criteria:}

1- Generalized obesity (BMI more than 35).

2- Previous abdominal scars compromising blood supply.

3- Heavy smokers.

4- Circumferential lower truncal excess.

5- Medical or psychiatric instability.

Standing anterior, oblique and lateral preoperative standard coloured digital photographs to the abdomen were taken. The pre-operative markings were made with the patient standing.

\section{Surgical procedures:}

All patients underwent lipoabdominoplasty in the supine position under general anesthesia. The maximum hip flexion allowed at operation was 30 degrees in all patients. Two grams of parenteral antibiotic e.g. $2^{\text {nd }}$ generation cephalosporin was given with induction. Followed with placement of a urinary catheter was placed to aid in intra and post-operative fluid management.

The procedure was started by abdominal liposuction as follow:

Stab incisions were made in the infra-umbilical skin for Tumescent Klein's solution injection (1 liter of lactated Ringer's solution, $25 \mathrm{cc}$ of $2 \%$ lidocaine, and 1cc of 1:1000 epinephrine solution was infused to attain adequate skin turgor (superwet technique) [8]. Breaking fat with cannula before suction application made easier suction of fat.

Liposuction was then performed in all areas of the abdomen and flanks including the epigastric area until adequate contouring was achieved (fat thickness, approximately $2 \mathrm{~cm}$ ). This was achieved by grasping the flaccid skin of abdominal wall towards the symphsis pubis for the ease of detecting of any fatty bulge.

Liposuction was initiated in the deeper plane using the thicker 5 and $4 \mathrm{~mm}$ cannulas and was finished in the superficial plane with the thinner $3 \mathrm{~mm}$ cannula using a fan technique to ensure a better homogeneous result and to prevent irregularities. The pinching maneuver and the observation of the thickness of the skin flap over the cannula indicated the point at which the liposuction should be finished.

After the completion of lipoplasty, abdominoplasty was carried out via a low suprapubic incision. The Anterior Abdominal wall flap undermining was performed till reach the xiphoid process. Supraumbilical flap undermining was performed only till the medial edge of the rectus abdominis muscles, this was the extent necessary to perform plication of their medial edges and umbilical transposition. After marking of the medial edges of the recti with methylene blue, the rectus sheath between medial edges of rectus muscles was plicated in a vertical fashion using two planes of sutures. The first plane was of separate sutures of non-absorbable material (Prolene ${ }^{\circledR} 1$ round needle) and the second plane was of continuous sutures of absorbable material (Vicryl® 2-0).

With the patient in the semiflexed position, the excess abdominal flap was excised. Starting at the cut edge of the flap where scarpa's fascia could be most easily identified and using scissors the deep fat in all zones of flap as far superiorly as the xiphoid and as far laterally as it was identifiable, was excised Fig. (2). The main incision was closed in two layers using 2-0 Vicryl ${ }^{\circledR}$ and 3-0 Vicryl ${ }^{\circledR}$ for closure of the subcutaneous layer and then running subcuticular 3-0 Monocryl®, was used to close the skin. The umbilicus was closed using interrupted 5-0 Monocryl® sutres.

\section{Post-operative management:}

Negative-suction drainage was left for approximately 5 days. An abdominal garmet was applied for 2-3 months to apply modest support to the abdomen. The patient was hospitalized for 2 to 3 days, unless otherwise indicated. Early ambulation was initiated to improve blood circulation in the lower extremities and diminish the risk of thrombosis. All patients were followed-up for at least three months, to assess the aesthetic results and detect and manage any complications. 

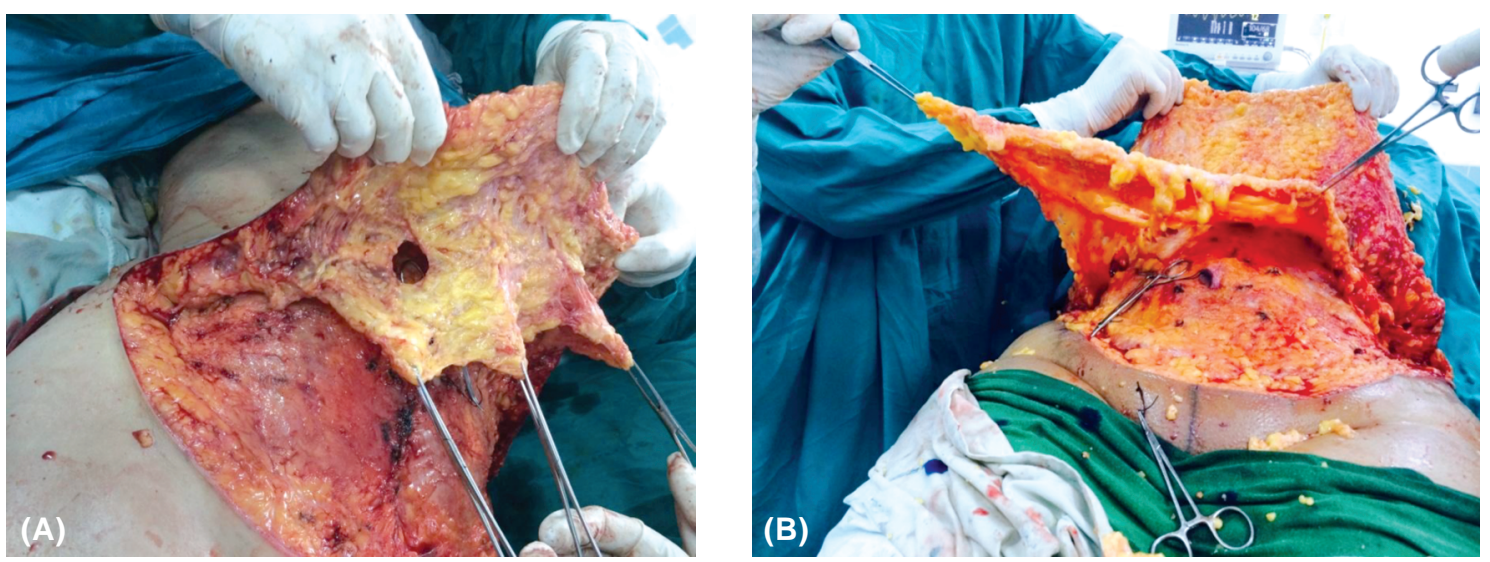

Fig. (2): (A) Dissection of sub-scarpal deep fat in all zones of the abdominal flap. (B) Direct excision of sub-scarpal fat.

\section{RESULTS}

Demographic criteria of the patients and clinical outcomes are shown in (Table 1). According to age, our patients ranged from 34-50years and the mean age at the time of operation was 41 years. Half of patients $(50 \%)$ were $<40$ years, while the other half $(50 \%)$ were $>40$ years (mean age 41 years). Half of the patients (50\%) had 2 offspirngs, 5 patients $(25 \%)$ had one offspring, 3 patients $(15 \%)$ had three offspirngs and two patients $(10 \%)$ had the maximal included parity which was 4 offsprigs.

The mean weight at the time of operation was $83.50 \pm 5.18 \mathrm{~kg}$ (range, $74.0-91.0 \mathrm{~kg}$ ). The mean height at the time of operation was $164.75 \pm 3.97 \mathrm{~cm}$ (range, 159.0-172.0cm). The mean body mass index at the time of operation was $30.80 \pm 2.18 \mathrm{~kg} / \mathrm{m}^{2}$ (range, $26.64-34.81 \mathrm{~kg} / \mathrm{m}^{2}$ ). As regards comorbidities, two patients were smokers, one patient was suffering from type 2 diabetes mellitus and two patients were hypertensive. As regards the past abdominal surgical history, ten patients never did any previous abdominal operations, nine patients had a previous caesarean section and one patient had previous appendectomy.

According to the post-operative evaluations, the mean total drain output was $944.0 \pm 88.10 \mathrm{ml}$ (range $800.0-1100.0 \mathrm{ml}$ ), the mean hospital stay was 3.75 \pm 0.91 days (range 3-6 days) and the mean hemoglobin level was $12.28 \pm 0.78 \mathrm{~g} / \mathrm{dl}$ preoperatively and $10.45 \pm 0.61 \mathrm{~g} / \mathrm{dl}$ post-operatively, and the average decrease was $14.82 \pm 2.06$ (no patient required a blood transfusion).

Table (1): Demographic criteria of the patients and clinical outcomes.

\begin{tabular}{|c|c|c|c|c|c|c|c|c|}
\hline No. & Age & $\begin{array}{c}\text { Body mass } \\
\text { index }\left(\mathrm{kg} / \mathrm{m}^{2}\right)\end{array}$ & Comorbidities & $\begin{array}{c}\text { Previous } \\
\text { abdominal surgery }\end{array}$ & $\begin{array}{l}\text { Hospital } \\
\text { stay }\end{array}$ & Complications & $\begin{array}{l}\text { Aesthetic } \\
\text { results }\end{array}$ & $\begin{array}{c}\text { Patient } \\
\text { satisfaction }\end{array}$ \\
\hline 1 & 37 & 28.82 & No & Cesarean section & 3 & No & Accepted & Satisfied \\
\hline 2 & 42 & 29.15 & No & No & 3 & No & Accepted & Satisfied \\
\hline 3 & 34 & 26.64 & No & Appendectomy & 4 & No & Accepted & Satisfied \\
\hline 4 & 38 & 27.21 & No & Cesarean section & 3 & No & Accepted & Satisfied \\
\hline 5 & 43 & 32.24 & No & No & 4 & No & Accepted & Satisfied \\
\hline 6 & 35 & 29.43 & No & No & 5 & seroma & Accepted & Satisfied \\
\hline 7 & 44 & 30.27 & No & Cesarean section & 3 & No & Accepted & Satisfied \\
\hline 8 & 39 & 31.48 & No & No & 3 & No & Accepted & Satisfied \\
\hline 9 & 36 & 28.64 & Smoker & Cesarean section & 6 & Dehescince and flap necrosis & Not accepted & Not satisfied \\
\hline 10 & 48 & 33.23 & Hypertension & No & 3 & No & Accepted & Satisfied \\
\hline 11 & 38 & 30.56 & No & Cesarean section & 4 & No & Accepted & Satisfied \\
\hline 12 & 41 & 29.40 & No & No & 3 & No & Accepted & Satisfied \\
\hline 13 & 39 & 27.20 & Smoker & No & 6 & Dehescince and flap necrosis & Not accepted & Not Satisfied \\
\hline 14 & 46 & 34.81 & No & Cesarean section & 3 & No & Accepted & Satisfied \\
\hline 15 & 34 & 31.40 & No & No & 5 & No & Accepted & Satisfied \\
\hline 16 & 50 & 33.60 & Hypertension & No & 3 & No & Accepted & Satisfied \\
\hline 17 & 35 & 29.20 & No & Cesarean section & 4 & No & Accepted & Satisfied \\
\hline 18 & 47 & 30.40 & Type 2 DM & Cesarean section & 4 & No & Accepted & Satisfied \\
\hline 19 & 44 & 31.50 & No & No & 5 & No & Accepted & Satisfied \\
\hline 20 & 46 & 27.80 & No & Cesarean section & 3 & No & Accepted & Satisfied \\
\hline
\end{tabular}


As regards the post-operative complications, two cases $(10 \%)$ were reported with flap dehesince, one case $(5 \%)$ with seroma and no cases of infection, DVT or pulmonary embolism were reported. An excellent aesthetic results was achieved, flap thinning by lipoabdominoplasty and resection of deep subscarpal fat gave our patients a smooth, flowing contour and improved overall silhouette

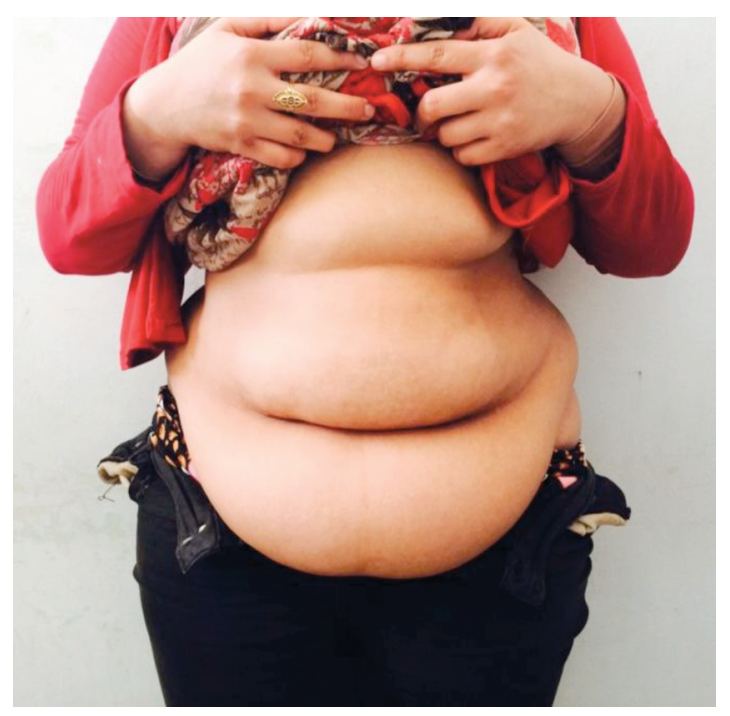

(A)

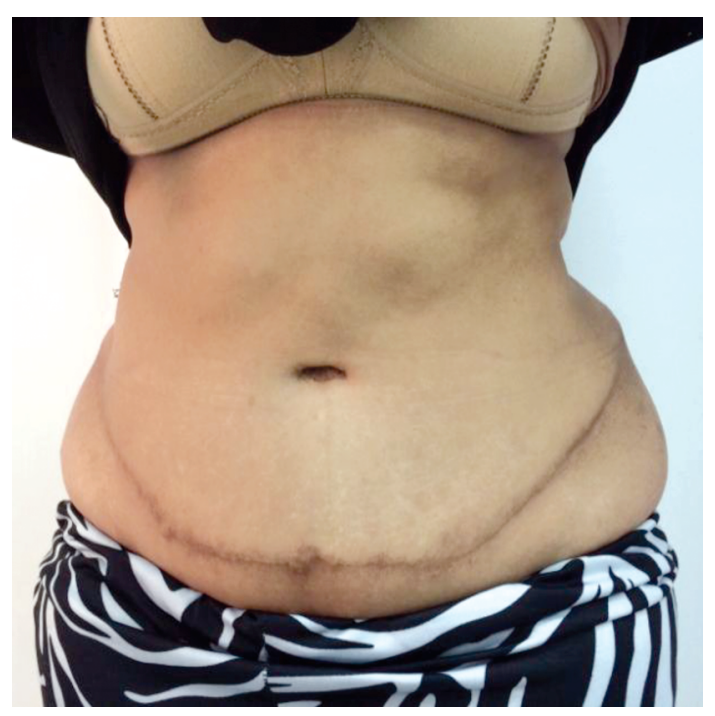

(C) and appearance of the abdomen, this was reflected on our patients satisfaction in whom 18 patients (90\%) were satisfied with the aesthetic outcome, in addition, aesthetic results as evaluated by a senior plastic surgeon not involved in the study were accepted in 18 cases (90\%). Figs. (3-5) show some results of this technique.

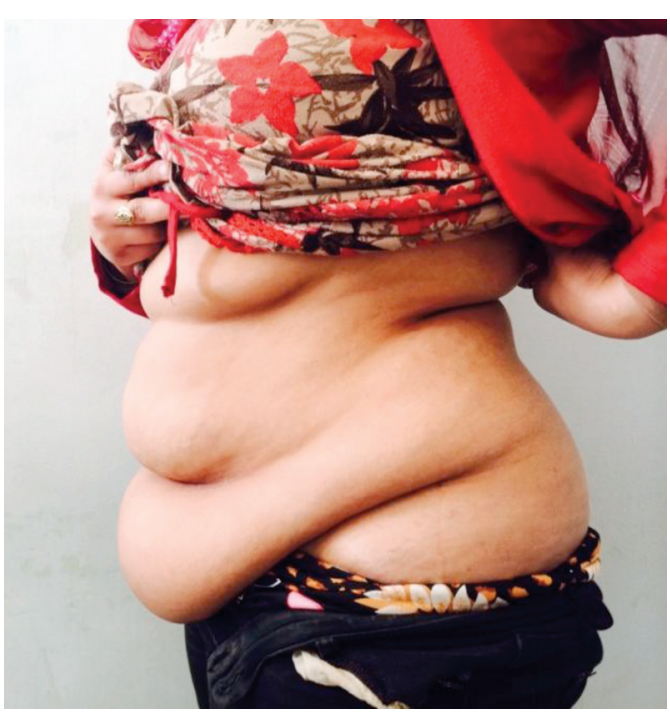

(B)

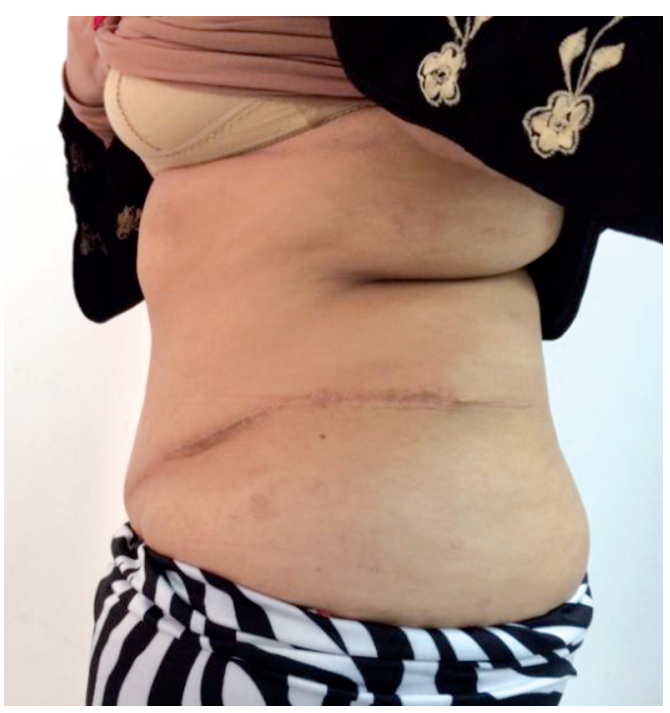

(D)

Fig. (3): Anterior and lateral pre-operative photo of a 43 years old patient, of BMI $32.24\left(\mathrm{~kg} / \mathrm{m}^{2}\right),(\mathrm{A}, \mathrm{B})$. Combined liposuction and direct resection of the sub-scarpal fat were performed. Note that deep fat removal facilitates matching the thickness of the superior and inferior edges of the incision $(C, D)$. 
Fig. (4): Anterior and lateral pre-operative photo of a 37 years old patient, of BMI $28.82\left(\mathrm{~kg} / \mathrm{m}^{2}\right),(\mathrm{A}, \mathrm{B})$. Combined liposuction and direct resection of the subscarpal fat were performed. Note that deep fat removal facilitates matching the thickness of the superior and inferior edges of the incision (C, D).

Fig. (5): Anterior and lateral pre-operative photo of a 38 years old patient, of BMI $30.56\left(\mathrm{~kg} / \mathrm{m}^{2}\right)$ with previous appendectomy scar (A, B). Combined liposuction and direct resection of the sub-scarpal fat were performed. Note that deep fat removal facilitates matching the thickness of the superior and inferior edges of the incision $(\mathrm{C}, \mathrm{D})$.
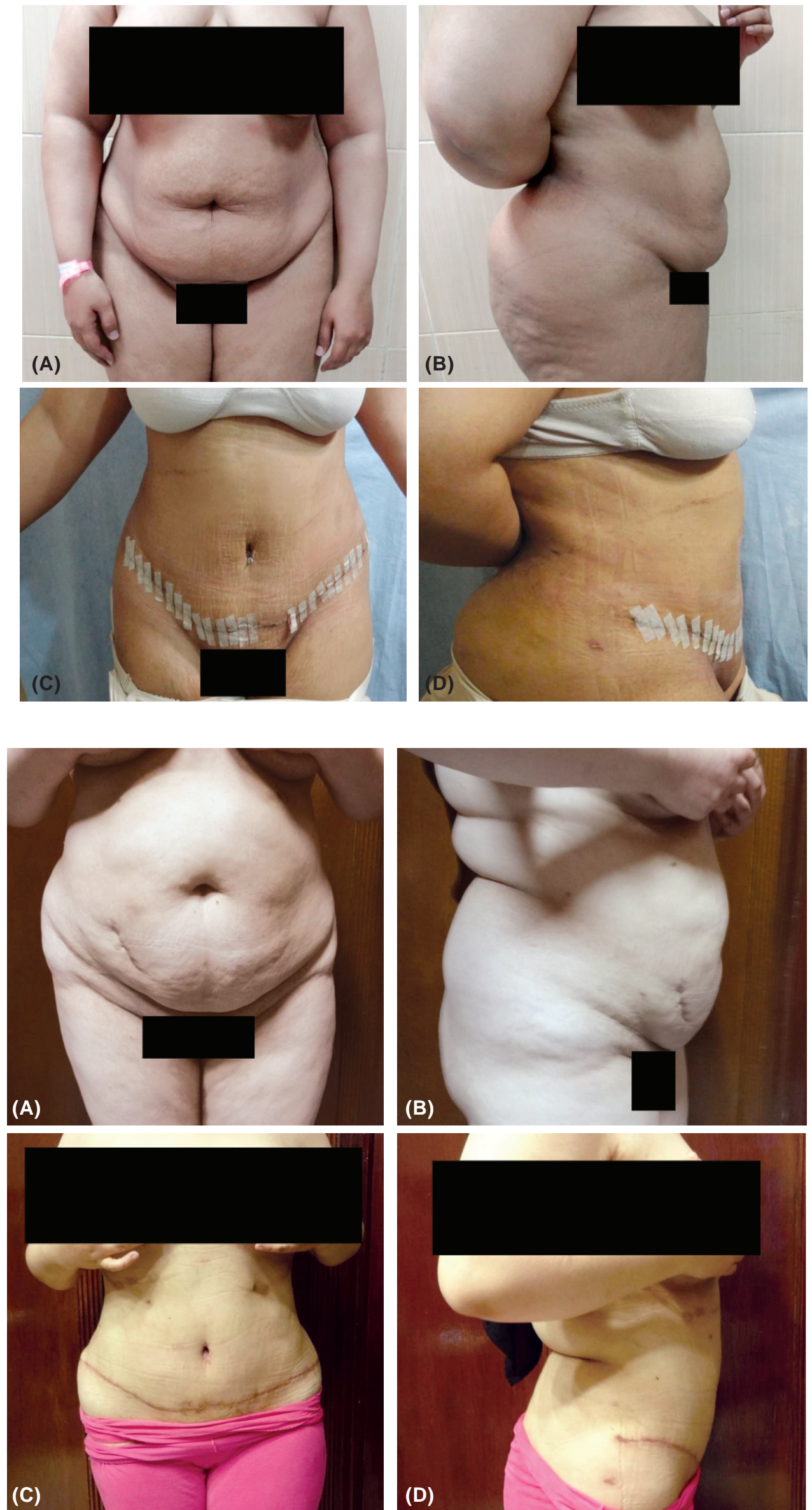


\section{DISCUSSION}

Correction of abdominal wall deformities is one of the most frequent procedures in plastic surgery, and the aesthetic, reconstructive, and functional aspects should always be considered. In its beginnings, abdominoplasty was limited to a direct resection of redundant tissues; later, additional treatment of the muscular wall was added. Extensive separation of the muscular fascia and fat layers above the navel by direct dissection was required to perform vertically oriented plication of the muscular aponeurosis from the xiphoid to the pubis.

For a long time during the evolution of the abdominoplasty technique, simultaneous liposuction was deemed unsafe because of complications such as necrosis of the abdominal flap due to devascularization by flap detachment, liposuction trauma, and to the deleterious effect of wound closure under tension. For these reasons, the introduction of abdominoplasty combined with liposuction was slow and with restrictions, until the idea of limited dissection above the navel appeared, preserving most of perforators of the flap, giving rise to the new lipoabdominoplasty era [9].

In 1987, Cardoso de Castro et al., [10] reported their experience combining limited-incision abdominoplasty with liposuction (lipoabdominoplasty) for 20 patients. With this technique, they were able to achieve a natural contour of the abdominal wall and umbilicus, maintenance of the mons pubis, and limited scarring. Dillerud [11], in a review of 487 patients undergoing lipoabdominoplasty, found that liposuction did not carry a significant additional risk when performed with abdominoplasty.

The risks liposuction presents to the central zones of an abdominoplasty flap were described by Matarasso, [12] who also advocated limited undermining to preserve perforators in the upper abdominal quadrants. The validity of limited undermining and zonal awareness as essential to flap survivability when liposuction is combined with abdominoplasty has been repeatedly confirmed [13].

In 2009, Robert R. Brink et al., [7] published their work about abdominoplasty with direct resection of subscarpal deep fat that showed that the incidence of limited necrosis at the incision line requiring subsequent scar revision was 0.7 percent in the 151 patients having abdominoplasty and 6.7 percent in the 30 patients having abdominoplasty combined with flank liposuction. Erythema and/or epidermolysis was seen in 4.8 percent of the abdominoplasty patients and 10 percent of the abdominoplasty/flank liposuction group. The rate of seroma formation in both groups was approximately 16.5 percent and concluded that direct excision of subscarpal fat does not subject any zone of the abdominoplasty flap to increased risks of vascular compromise and that it is a safe technique that provides excellent abdominoplasty results. The following factors may have played some role in contributing to their low rate of tissue compromise:

Tangential resection of all deep adipose tissue may diminish metabolic demand enough to provide the flap with a survival advantage. In addition, the removal of subscarpal fat from the part of the flap that is advanced to cover the area from umbilicus to pubis facilitates healing by debulking the flap where closure tension is highest (removal of deep fat from this area also eliminates the characteristic step-off deformity along the incision line resulting from mismatched tissue thicknesses). The Perineoumbilical and supra-neoumbilical midline defatting provides additional relief of closure tension at the midline.

In the current study, we performed for all cases lipoabdominoplasty with limited supraumblical paramedian undermining with thining of the anterior abdominal wall flap through resection of the deep subscarpal fat, the outcoming results showed decreased rate of early and late complications. Only one case of seroma was reported $(5 \%$ of cases) which is very comparable to the results of the literature. Only two case of mild wound dehesince were reported (10\% of cases) who were smokers, showing the negative impact of smoking on flap circulation. No case of infection, heamatoma, DVT or pulmonary embolism was reported.

Patient satisfaction is multifactorial and includes perceptions, motivations, and expectations. A productive approach for clinical care and research is to ask how patients benefit from plastic surgery, which is an integral part of completing the treatment of patients seeking aesthetic surgery.

Song et al., [14] investigated patients submitted to body contouring after 3 and 6 months and found out better quality of life and body image but not mood, which remained stable. These results are similar to the results of quantitative and qualitative research studies that describe improvement in body image, self-esteem, quality of life, and mental health $[\mathbf{1 5}, \mathbf{1 6}]$.

Among the largest studies with 199 patients addressing patient satisfaction status, post- 
abdominoplasty is the contribution by Hensel et al., [17] with a patient satisfaction rate of $86 \%$. In our study the patient satisfaction was measured by a binary scale including satisfied or not satisfied and the results was 18 cases of satisfaction (90\%). We suggest that patients considering aesthetic surgery should be informed about the high probability of developing complications, so that they develop a fair and realistic expectation of outcomes of such surgeries, and consequently, their dissatisfaction should be mitigated by fair expectation. The assessments of the aesthetic results were done by senior plastic surgeons not involved in the study, and $90 \%$ of cases were accepted.

\section{Conclusion:}

Lipoabdominoplasty is a powerful and safe body sculpturing tool. In combination with other body contouring procedures, it can lead to a comprehensive body transformation anatomical, physiological, and psychological. The subscarpal fat needs be removed to attain the aesthetic goals of abdominoplasty, and this can be accomplished safely with an open direct approach.

\section{REFERENCES}

1- Kelly H.: A report of gynecologic diseases (excessive growth of fat). Johns Hopkins Med. J., 10: 197, 1899

2- Pitanguy I.: Abdominal lipectomy: An approach to it through analysis of 300 consecutive cases. Plast. Reconstr. Surg., 40: 384, 1967.

3- Garrido D.E., Aponte Y.M., Behnam A.B., Keeshin T., Sinha V., Evans K.K. and Salgado C.J.: Updates in Abdominal Wall Reconstruction; Anaplastology, 2: 21611173,2013

4- Taylor G.I. and Daniel R.K.: The anatomy of several free flap donor sites. Plast. Reconstr. Surg., 56: 243, 1975.

5- Hester T.R. Jr., Nahai F., Beegle P.E. and Bostwick J. III.: Blood supply of the abdomen revisited, with emphasis on the superficial inferior epigastric artery. Plast. Reconstr. Surg., 74: 657, 1984.

6- Worseg A.P., Kuzbari R., Hubsch P., et al.: Scarpa's fascia flap: Anatomic studies and clinical application, Plast. Reconstr. Surg., 74: 1368, 1984.

7- Brink R.R., Beck J.B. and Anderson C.M.: Abdominoplasty with direct resection of deep fat. Plast. Reconstr. Surg., 123: 1597, 2009

8- Justin B.: Outcome Analysis of Combined Lipoabdominoplasty versus Conventional Abdominoplasty. Plast. Reconstr. Surg., 121: 1821, 2008.

9- Saldanha O.R., Pinto E.B., Matos Jr. W.N., Lucon R.L., Magalhães F. and Bello E.M.: Lipoabdominoplasty without undermining. Aesthet. Surg. J., 21 (6): 518-26, 2001.

10- Cardoso De Castro C., Cupello A.M. and Cintra H.: Limited incisions in abdominoplasty. Ann. Plast. Surg., 19 (5): 436-47, 1987.

11- Dillerud E.: Abdominoplasty combined with suction lipoplasty. A study of complications, revisions, and risk factors in 487 cases. Ann. Plast. Surg., 25 (5): 333-8, 1990.

12- Matarasso A.: Liposuction as an adjunct to full abdominoplasty. Plast. Reconstr. Surg., 95: 829, 1995.

13- Brauman D.: Liposuction abdominoplasty: An evolving concept. Plast. Reconstr. Surg., 112: 288, 2003.

14- Song A.Y., Rubin J.P., Thomas V., Dudas J.R., Marra K.G. and Fernstrom M.H.: Body image and quality of life in post massive weight loss body contouring patients. Obesity, 14 (9): 1626-36, 2006.

15- Stuerz K., Piza H. and Kinzl J.F.: The impact of abdominoplasty after massive weight loss: A qualitative study. Ann. Plast. Surg., 71 (5): 547-9, 2013.

16- Papadopulos N.A., Staffler V., Mirceva V., Henrich G., Papadopoulos O.N., Kovacs L., et al.: Does abdominoplasty have a positive infl uence on quality of life, selfesteem, and emotional stability? Plast. Reconstr. Surg., 129 (6): 957-62, 2012.

17- Hensel J.M., Lehman J.A., Tantri M.P., Parker M.G., Wagner D.S. and Topham N.S.: An outcomes analysis and satisfaction survey of 199 consecutive abdominoplasties. Ann. Plast. Surg., 46 (4): 357-63, 2001. 